\title{
Despopulação neuronal cardíaca em hamsters (Mesocricetus auratus) cronicamente infectados com o Trypanosoma cruzi
}

\author{
Cardiac neuronal depopulation in hamsters (Mesocricetus \\ auratus) chronically infected with Trypanosoma cruzi \\ Edmundo Chapadeiro, Elione Lages Silva, Anita C. M. Silva, \\ Patrício fernandes e luis Eduardo Ramirez
}

Resumo Com o objetivo de se obter um modelo experimental que permitisse estabelecer a despopulação (desnervação) neuronal cardíaca procurou-se pesquisar o comportamento do sistema nervoso intracardíaco em hamsters cronicamente infectados com o T. cruzi. Para tal fim, realizaram-se contagens dos neurônios do plexo nervoso autonômico intracardíaco em hamsters inoculados com 35.000 formas sangüíneas de três cepas diferentes, sacrificados 5 , 8 e 10 meses depois da infecção. Demonstrou-se, pela primeira vez, destruição neuronal significativa num modelo experimental, similar à que ocorre na doença de Chagas humana.

Palavras-chaves: Despopulação neuronal cardíaca. Desnervação parassimpática. Doença de Chagas experimental. Hamster.

\begin{abstract}
The aim of this study was to obtain an experimental animal model of destruction of cardiac neurons in order to investigate the behavior of the cardiac nervous system of hamsters chronically infected with Trypanosoma cruzi. We counted the neuronal cells of the cardiac autonomic nervous plexus in hamsters inoculated with 35000 blood forms of three different T. cruzi strains and killed 5, 8 and 10 months after infection. We showed for the first time severe neuronal destruction in an experimental animal model with characteristics similar to those observed in human Chagas'disease.
\end{abstract}

Key-words: Neuronal cardiac despopulation. Parasympathetic denervation. Experimental Chagas' disease. Hamster.

Uma das alterações morfológicas mais importantes que ocorrem durante a fase crônica da infecção chagásica humana é a lesão do plexo nervoso parassimpático dos órgãos ocos, especialmente do coração e do tubo digestivo, acompanhada por destruição neuronal. Esta despopulação9 11 (desnervação) é considerada a responsável pela patogênese das alterações cardíacas (arritmias, extrassístoles, etc.), assim como das manifestações digestivas, (megaesôfago e megacólon) que ocorrem na doença de Chagas humana. Estudos experimentais para estabelecer tal correlação foram feitos somente no rato 679 . Contudo, neste como em outros animais 345 , não foi observada perda neuronal significativa11 1214 similar à observada na doença humana.

$\mathrm{Na}$ busca de um novo modelo experimental para o estudo da doença de chagas, como proposto pela Organização Mundial da Saúde16,

Faculdade de Medicina do Triângulo Mineiro.

Endereço para correspondência: Dr. Edmundo Chapadeiro. Disciplina de Patologia Departamento de Ciências Biológicas da Faculdade de Medicina do Triângulo Mineiro. Praça Manoel Terra 330, 380015-050 Uberaba, MG.

Tel: 5534 318-5258.

E-mail: pgpathum_fmtm@mednet.com.br

Recebido para publicação em 3/4/98. 
verificou-se que o sistema nervoso intracardíaco do hamster apresentava-se lesado pelo mesmo processo inflamatório que ataca o miocárdio14 Em vista disso, procurou-se detectar se também nesse animal, cronicamente infectado pelo T. cruzi, ocorre destruição neuronal significativa nos gânglios do mencionado plexo, na tentativa de se obter um novo modelo que permita estabelecer uma correlação mais precisa entre a desnervação e a disfunção autonômica parassimpática.

\section{MATERIAL E MÉTODOS}

Três grupos de dez hamsters de ambos os sexos pesando entre 90 e $130 \mathrm{~g}$ foram infectados com 35.000 tripomastigotas sangüíneos das cepas $\mathrm{Y}$, Benedito e Vicentina; as duas últimas isoladas em nosso laboratório de pacientes chagásicos com a forma indeterminada e mista (cardíaca e digestiva) respectivamente. Quinze hamsters não infectados foram usados como controles. Os animais infectados foram identificados previamente e colocados em uma única gaiola assim como os do grupo controle. Dois animais infectados e um do grupo controle foram retirados, aleatoriamente, no $5^{\circ}$, $8^{\circ}$ e $10^{\circ}$ mês pós infecção e sacrificados, utilizando-se éter etílico anestésico. Os hamsters restantes foram utilizados em outros experimentos. Dos espécimes sacrificados, três pertenciam à cepa Vicentina, dois à cepa Benedito e um à cepa Y.

Durante a necropsia, os corações foram retirados e fixados in totum em formalina a $10 \%$, depois de secção sagital dos mesmos. Em seguida, estas metades eram incluídas em um

de morte e/ou substituídas por gliose (satelitose).

\section{RESULTADOS}

À autópsia, os corações dos animais infectados eram aumentados de volume, congestos e com as cavidades dilatadas quando comparados com os controles. Microscopicamente, os corações mostravam inflamação multifocal ou zonal, caracterizada por infiltração de células mononucleares (macrófagos e linfócitos) e mastócitos no epicárdio (epicardite) e miocárdio (miocardite). No epicárdio, o infiltrado atingia não só o tecido conjuntivo frouxo, mas também os filetes nervosos (neurite) e os gânglios (ganglionite e periganglionite) do plexo nervoso parassimpático. Além do infiltrado só bloco de parafina e cortados em secções de $6 \mu \mathrm{m}$ somente uma em cada seis secções era montada em lâmina, a fim de se proceder a contagem dos neurônios e evitar que estes fossem contados mais de uma vez, visto que os mesmos têm um diâmetro médio de $30 \mu \mathrm{m}$. Assim,

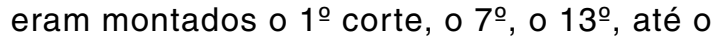
esgotamento do material incluído.

O número total de secções montadas em lâminas variou de 200 a 300, devido à variação volumétrica do órgão como conseqüência não somente do dano cardíaco, mas também do ganho do peso do animal durante a experiência. As secções foram coradas pelo Giemsa modificado para tecidos, para uma melhor identificação dos neurônios e maior precisão nas contagens; cortes adicionais, não usados para a contagem foram coradas pela hematoxilina-eosina e pela coloração tricrômica de Masson para estudo histológico das lesões.

Foram contados todos os neurônios íntegros e/ou com sinais de degeneração, ao microscópio óptico (400x) excluindo-se as células com sinais

inflamatório, os gânglios mostravam alterações neuronais caracterizadas por tigrólise, hipercromasia citoplasmática e sinais de morte celular (satelitose) com proliferação do estroma conjuntivo-vascular (Figuras 1 e 2). Em três animais (dois infectados com a cepa Vicentina e um com a cepa Benedito) foram detectados ninhos de amastigotas no miocárdio.

A Tabela 1 apresenta os resultados da contagem dos corpos neuronais, que variou de 11 a 428 nos animais infectados e de 705 a 810 nos animais controles. Os testes estatísticos foram dispensados, visto que, o maior número de neurônios dos animais infectados estava 


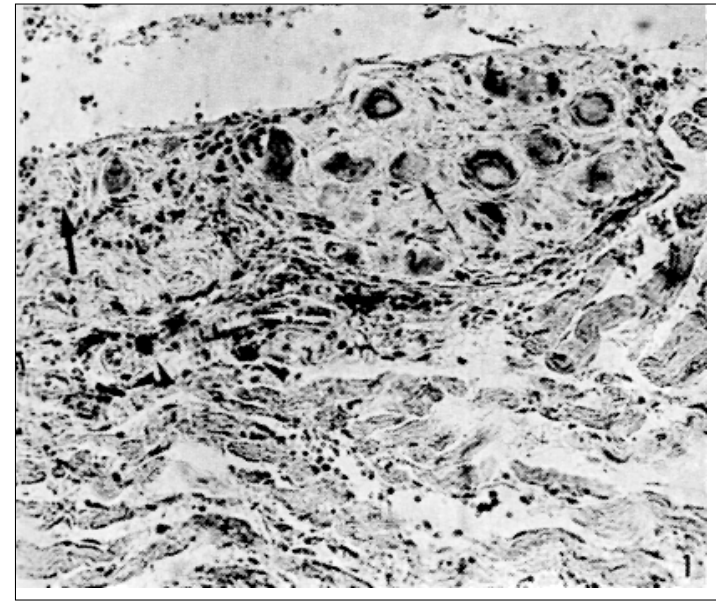

Figura 1 - Ganglionite e periganglionite: infiltrado inflamatório mononuclear e de mastócitos (cabeças de seta). Neurônios hipotróficos, degenerados (tigrólise: seta fina) e hipercromáticos. Abundante estroma conjuntivo vascular com sinais de proliferação glial (seta grossa). Giemsa, 400x.

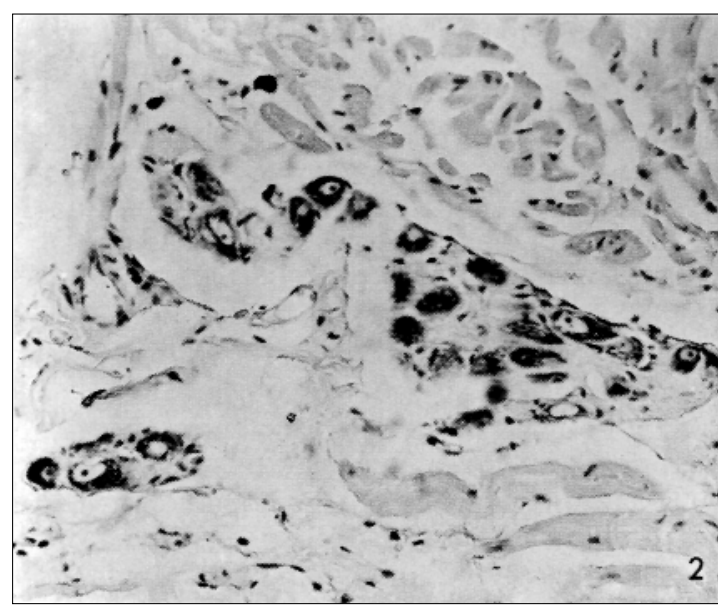

Figura 2 - Três gânglios constituídos por neurônios com morfologia e coloração de aspecto normal, sustentados por estroma frouxo escasso e delicado. Giemsa, 400x.

Tabela 1 - Lesões e contagem neuronal nos gânglios atriais em hamsters cronicamente infectados com diferentes cepas do Trypanosoma cruzi.

\begin{tabular}{|c|c|c|c|c|c|c|}
\hline \multirow[b]{2}{*}{ Cepa } & \multicolumn{3}{|c|}{ Hamsters chagásicos } & \multicolumn{3}{|c|}{ Hamsters controles } \\
\hline & Sexo & ganglionite & № neurônios & Sexo & ganglionite & № neurônios \\
\hline Benedito & $\mathrm{F}$ & presente & 0 & $\mathrm{M}$ & ausente & 810 \\
\hline Benedito & $\mathrm{F}$ & presente & 223 & $\mathrm{~F}$ & ausente & 790 \\
\hline Vicentina & M & presente & 141 & $\mathrm{~F}$ & ausente & 705 \\
\hline Vicentina & $\mathrm{F}$ & presente & 11 & & & \\
\hline Vicentina & $\mathrm{F}$ & presente & 16 & & & \\
\hline Y & M & presente & 428 & & & \\
\hline Média & & & 136.5 & & & 768.3 \\
\hline
\end{tabular}

bem abaixo do menor número daqueles dos animais controles.

\section{DISCUSSÃO}

O sistema nervoso autônomo parassimpático cardíaco do hamster está localizado nas paredes atriais e especialmente no septo interatrial. Consiste de gânglios que recebem fibras vagais (fibras pré-ganglionares) das quais saem fibras pós-ganglionares para inervar o miocárdio e outras estruturas do coração. O papel desse sistema não está, ainda, totalmente esclarecido, mas se admite que na doença de Chagas humana ele é o responsável pela disfunção cardíaca parassimpática, a qual, por sua vez, pode levar a outras manifestações mais importantes (arritmias, bloqueios de ramo, cardiomegaliam, lesão vorticilar, etc). Porém, uma correlação direta entre essa despopulação e a disfunção parassimpática de animais chagásicos crônicos não foi confirmada6. 
Estudos parasitológicos e histopatológicos das fases aguda e crônica da infecção chagásica em hamster nos levaram a concluir que este animal é um modelo útil para o estudo dessa doença14, visto que apresenta lesões da cardiopatia associadas com ganglionite e neurite do plexo autonômico parassimpático cardíaco, como também lesões do trato digestivo, caracterizadas por infiltrado mononuclear constituído por macrófagos, linfócitos, plasmócitos e mastócitos localizado na musculatura e nos gânglios intramurais.

Em trabalho anterior, realizado em hasmters inoculados com as mesmas três cepas, a fim de estudar seu comportamento biológico, tivemos a oportunidade de observar que, tanto o tecido muscular (principalmente o liso) quanto o tecido conjuntivo (principalmente gorduroso e macrofágico) eram intensamente infectados desde o início (dados não publicados). No presente estudo demonstramos, pela primeira vez, despopulação significativa do plexo cardíaco em um modelo experimental da infecção por $T$. cruzi durante a fase crônica, muito similar àquela observada em humanos com a doença de Chagas 10 11, possivelmente como conseqüência do processo inflamatório (ganglionite).

Embora pareça pequeno o número de animais infectados para a contagem neuronal, observou-se uma intensa redução no número de neurônios do plexo nervoso autônomo intracardíaco, em todos os animais estudados, que variou de 0 a 428 neurônios quando comparada com os controles. Em todos os animais infectados, o número total de neurônios esteve muito abaixo do número total dos neurônios dos animais controles, não havendo superposição das duas distribuições de valores, o que não justifica a aplicação de qualquer teste estatístico. Ainda que não se tenha detectado neurônios no coração de um dos animais infectados, isso não exclui que alguma célula nervosa pudesse ser detectada.

Em outros modelos, tais como, ratos 679 13, camundongos 5 , Calomys callosus 45 e cães 3 , embora apresentem lesões similares dos gânglios autonômicos parassimpáticos cardíacos, não tem sido demonstrada destruição neuronal significativa. De tal maneira, o hamster parece ser, até agora, o único modelo experimental que apresenta despopulação (desnervação) neuronal importante, o que em alguns casos, chega a ser total, como acontece também no homem 12 .

Para a demonstração da disfunção autonômica parassimpática correspondente, seria necessária a aplicação de testes de disfunção cardíaca, tais como o baroreflexo e a análise espectral do eletrocardiograma que não foram realizados, ainda, neste animal

Em conclusão, a despopulação (desnervação) parassimpática observada em hamsters infectados pelo $T$. cruzi pode ajudar a esclarecer o papel controverso desta condição na patogenia das manifestações clínicas e morfológicas da doença humana, fato que torna este animal um

modelo útil para a elucidação da disfunção autonômica parassimpática na cardiopatia

chagásica humana15 e, provavelmente, em outras cardiopatias 128 .

\section{REFERÊNCIAS BIBLIOGRÁFICAS}

1. Bohm GM. South Africam endomyocardiopathy and endomyocardial fibrosis. A critical review. Revista do Instituto de Medicina Tropical de São Paulo 10:88-108, 1968.

2. Bristow JD, Hondur AJ, Pickering GW, Sleight P, Smyth HS. Diminished baroreflex sensitivity in high blood pressure. Circulation 39:48-54, 1969.

3. Caliari MV, Lana M, Oliveira ER, Tafuri WL. Cardic plexus of dogs experimentally infected with Trypanosoma cruzi: inflammatory lesions and quantitative studies. Revista da Sociedade Brasileira de Medicina Tropical 28:13-17, 1995.

4. Carvalho CAF, Borges N, Martin ZO, De Souza RR.
Morphologic and quantitative studies on cardiac ganglia of chronic chagasic Calomys callosus. Memórias do Instituto Oswaldo Cruz 87(Suppl. II): 97, 1992.

5. Carvalho CAF, Maifrino LBM, Borges N, Martins ZO, De Souza RR. Comparative study on cardiac ganglia of chronic chagasic Calomys callosus and mice. Memórias do Instituto Oswaldo Cruz 88(Suppl):109, 1993.

6. Chapadeiro E, Florêncio RFC, Afonso PC, Beraldo PSS, Jesus PC, Junqueira Jr LF. Neuronal couting and parasympathetic dysfunction in the heart of chronically Trypanosoma cruzi infected rats. Revista do Instituto de Medicina Tropical de São Paulo 33:337-341, 1991.

7. Chapadeiro E, Beraldo PSS, Jesus PC, Fernandes PD, Junqueira Jr LF. Estudo dos neurônios do plexo cardíaco na infecção aguda pelo Trypanosoma cruzi em ratos albinos. Revista Brasileira de Medicina Tropical 27:79-81, 1994.

8. Duchen LW, Anjorin A, Watkins PJ. Pathology of autonomic neuropathy in diabets mellitus. Annals of 
Internal Medicine 92:301-303, 1971.

9. Junqueira Jr LF, Beraldo PSS, Chapadeiro E, Jesus PC. Cardiac autonomic dysfunction and neuroganglionitis in a rat model of chronic Chagas' disease. Cardiovascular Research 26:324-329, 1992.

10. Köberle F. Patogenese dos "megas". Revista Goiana de Medicina 3:101-110, 1958.

11. Köberle F. Chagas' disease and Chagas' syndrome. The pathology of American trypanosomiasis. Dawes B (ed) Advances in Parasitology. vol 6. Academic Press, New York, 63-116, 1968.

12. Lopes ER. Contribuição ao estudo dos gânglios cardíacos (Sistema cardíaco autônomo) em chagásicos crônicos. Hospital 79:1421-1423, 1965.

13. Oliveira JSM. A concentração de noradrenalina miocárdica em ratos sob diversas condições experimentais com destaque à infecção pelo $T$. cruzi. Tese de Mestrado. Faculdade de Medicina de Ribeirão Preto, Universidade de São Paulo, Ribeirão Preto, 1977.

14. Ramirez LE, Lages-Silva E, Soares JR, Chapadeiro E. The hamster (Mesocricetus auratus) as experimental model in Chagas' disease: parasitological and histopathological studies in acute and chronic phases of Trypanosoma cruzi infection. Revista da Sociedade 